\title{
Time Management of Open Lower-Leg Fractures in Morocco
}

\author{
Adonis Magoumou', Yassir El Andaloussi' ${ }^{1}$, Simohamed Fahsi' ${ }^{1}$, Othmane Hiba1, \\ Mustapha Fadili1, Mohamed Nechad1, Mohamed Ouarab1, Fatima Zahra Widad2, \\ Samira Nani' ${ }^{2}$, Samira Hassoune ${ }^{2}$, Abderrahmane Maaroufi ${ }^{2}$ \\ ${ }^{1}$ Department of Orthopedic Traumatology, Wing 4, Chu Ibn Rochd, Casablanca, Morocco \\ ${ }^{2}$ Laboratory of Epidemiology, Faculty of Medicine and Pharmacy, Casablanca, Morocco \\ Email: constantcm@yahoo.fr
}

Received 25 June 2014; revised 21 July 2014; accepted 30 August 2014

Copyright (C) 2014 by authors and Scientific Research Publishing Inc.

This work is licensed under the Creative Commons Attribution International License (CC BY).

http://creativecommons.org/licenses/by/4.0/

(c) (i) Open Access

\begin{abstract}
Background: It is recommended that the management of open lower-leg fractures should occur within six hours to avoid complications affecting both prognosis and functionality. This study aimed to evaluate the time taken for each step of management, identify causes of delay, and propose solutions to reduce the rate of complications. Patients and methods: This was a prospective study involving 153 patients treated from January 2011 to December 2012. Standardized data collection forms documented the times taken for each management step from the accident until surgical intervention. Results: For patients admitted directly to our institution, median time to surgical debridement from arrival was 5 hours. Median time for bone fixation was 24 hours. External fixation was used in 119 patients. There were several causes of delay; lack of financial resources was the most common. Certain causes of delay were significantly correlated with time to debridement. However, although $86.7 \%$ of patients who developed an infection had a time from injury to debridement greater than six hours, there was no statistically significant association between infection and delay beyond six hours $(p=0.403)$. Conclusion: By identifying causes of treatment delay, we hope to be able to avoid complications, and therefore reduce the socioeconomic impact of these important surgical emergencies.
\end{abstract}

\section{Keywords}

Open Fracture, Lower-Leg Fracture, Chu Ibn Rochd, Casablanca

\section{Introduction}

Open fractures of the lower-leg are an orthopaedic emergency. Ideal management includes antibiotics and pro-

How to cite this paper: Magoumou, A., El Andaloussi, Y., Fahsi, S., Hiba, O., Fadili, M., Nechad, M., Ouarab, M., Widad, F.Z., Nani, S., Hassoune, S. and Maaroufi, A. (2014) Time Management of Open Lower-Leg Fractures in Morocco. Open Journal of Emergency Medicine, 2, 53-61. http://dx.doi.org/10.4236/ojem.2014.23010 
phylaxis against tetanus and thromboembolic disease, debridement and irrigation within six hours, followed by operative fixation [1]-[3]. However, this is not always achieved in the central university hospital (CUH) of Casablanca; Non-availability of fixation material in our hospital requires us to prescribe the required equipment for the patient, and delay bone fixation pending purchase of that equipment. In 1987 a series of 70 patients treated at the orthopedic trauma service of the University Hospital of Casablanca reported times to bone fixation from one week to one month [4]. It is not known whether this has improved since.

Many authors, especially in similar contexts to our own, have addressed the issue of open lower-leg fractures and their complications, but the actual times of each management step and potential causes of therapeutic delay have not yet been elucidated.

This study aimed to evaluate the time taken for each step of management, identify causes of delay, and propose solutions to reduce the rate of complications.

\section{Materials and Methods}

This was a prospective study of 153 patients treated at Orthopaedic Trauma Department of Casablanca, over a period of 24 months (January 2011 to December 2012). During this time, 765 extremity fractures were received. (Open lower-leg fractures made up 20\% of the traumatic pathology in our orthopedic department during the period of study).We included all patients aged at least 15 years with open lower-leg fracture, admitted directly to our institution or transferred from a regional hospital without prior care, who received surgical treatment. Exclusion criteria: patients with lower-leg fractures treated conservatively; open-from-within fractures that had been closed on arrival to hospital; patients who died before surgery.

\subsection{Normal Flow of Patients in $\mathrm{CUH}$}

The normal flow of patients in our institution involves the patient being transported into the closest hospital to the accident scene. Once in hospital; the patient receives necessary first aid treatment and is either admitted there or transferred to CUH. If CUH is the closest hospital, the patient gets admitted directly without having to go through another health centre. If the patient is transferred or evacuated from another health centre to the CUH, his admission into CUH is described as indirect. Once in CUH, patients are assessed by the general physician on duty, and prioritized for diagnostic imaging and further management according to clinical urgency. Occasionally imaging needs to be repeated if of insufficient quality on first attempt. Once adequate imaging is achieved, the physician refers the patient for review by relevant specialists before admission and definitive management as appropriate. If present, the patient's family and friends will assist him throughout his hospital stay. If bone fixation is required, the necessary materials are prescribed (intramedullary nail or external fixation) and the patient is admitted pending operation, until the materials have been purchased. Nursing staff work in eight hour shifts with handovers at 2 pm, 7 am and 8 pm. During Ramadan work is nearly completely suspended between 7 - 8 pm while the fast is broken.

In Morocco the cost of fixing depends on the type of fixation material: Hoffmann: 500 Euros; Ilizarov: 1200 Euros; Orthofix: 3000 Euros; intramedullary nail: 200 Euros.

\subsection{Data Collection}

Data were collected using a standardised survey form, documenting the times taken for each management step from patient arrival to each stage of treatment. In addition, time to debridement was also calculated from the time of injury. Eight time-points were studied: arrival, request for radiography, completion of radiography, hospitalization, debridement, prescription of fixation material, purchase of fixation material, bone fixation.

\subsection{Ethics}

Patients or their relatives gave informed consent to be part of the study.

\subsection{Statistical Analysis}

Data were entered and analyzed using SPSS 16.0 and $p<0.05$ was considered significant. Chi-squared test, ttest, analysis of variance (ANOVA), and nonparametric tests as appropriate, were used to determine the factors 
influencing the time taken to debridement and bone fixation. Multivariate analysis was performed by binary logistic regression.

\section{Results}

\subsection{Age, Sex and Etiology}

Patients were aged between 15 and 75 years, with a median age of $26.92 .2 \%$ were male. The most common etiology was public road accident (86.7\%), followed by high-level falls $10.6 \%$ and assaults $2.7 \%$.

\subsection{Mode of Transportation and Time of Admission}

$39.9 \%$ of patients were admitted directly to the emergency room without going through another health facility. Non-paramedic ambulances were the most frequent method of attendance $(90 \%)$. Other means of transportation included private cars. Median time of arrival was two hours from injury scene (range 0.25 to 17 hours). Median time for direct arrival at our institution was 0.75 hours (range 0.25 to 2.5 hours).

All patients were admitted through the emergency room. Haemodynamic shock requiring ICU admission was present in $3.6 \%$ of our patients.

Grades of wound according to the Cauchoix and Duparc classification [5] are detailed in Table 1. 60/153 patients had associated injuries: other fractures ( 9 cases), head injuries (40 cases) and chest injuries (11 cases).

Radiological assessment included anteroposterior and lateral radiographs of the lower-leg, including both knee and ankle. Pelvic and chest x-rays were routinely performed following road traffic accidents. Other radiological assessments depended on the injuries identified. Median time to initiation of diagnostic imaging was 0.5 hours (range 0.25 to 3 hours). Median time to completion of diagnostic imaging was 2 hours (range 0.5 to 3 hours).

\subsection{Treatment}

Median time to admission to the orthopaedic unit was five hours (range 1 to 22 hours). Median length of hospital stay was five days (range 3 to 53 days). Initial debridement consisted of washing with antiseptic solution and saline. Surgical exploration defined the grade of injury, removed debris, foreign bodies, and excised devitalized bruised areas. Median time of debridement was five hours (range 1.5 to 6.5 hours). Median time of debridement from the injury scene was seven hours (range 2 to 22 hours). Median time to prescription of fixation material was 24 hours (range 1 to 72 hours). Median time to purchase fixation material was 24 hours (range 0.5 to 144 hours). Median time for bone fixation was 24 hours (range 20 to 168 hours).

External fixation (EF) was used in 119 patients (77.8\%) intramedullary nailing (IN) in 34 (22.2\%). Median time for bone fixation using an external fixator was 24 hours, and median time of fixation using intramedullary nailing was also 24 hours.

\subsection{Causes of Delay in Care}

There are multiple factors associated with surgical delay including both patient and system-specific variables. Patient factors include the presence of haemodynamic instability, associated traumatic injuries, and lower-leg skin condition. System factors include timing of arrival to the definitive treatment center, and hospital efficiency and protocols for management including: unavailability of care givers, team changeovers, radiographic equipment breakdown, striking by medical staff, breaking the fast during Ramadan, needing to repeat radiography, and lack of financial resources. In our study, lack of financial means was the leading cause of delayed care for patients (Figure 1).

Statistical analysis showed significant associations between the time from injury to debridement and patient flow ( $p<0.05)$; unavailability of medical staff $(p<0.05)$; and type of material used $(p<0.05)$. There were no other statistically significant associations with debridement or bone fixation times (Table 2 ).

\subsection{Infection Rates}

15 Patients were infected during hospitalization or within two weeks of operation; $86.7 \%$ of patients with infection had a time from injury to debridement greater than 6 hours (Table 3 ). 
Table 1. Distribution of patients according to Cauchoix and Duparc grade.

\begin{tabular}{cccc}
\hline Wound type & Clinical appearance & Number (\%) & Percentage \\
\hline TYPE I & Punctate or small linear wound, without peeling or bruising. Can be sutured without tension & 98 & 64 \\
TYPE II & Contused wound edges, or detached or bruised surrounding skin. Some risk of secondary necrosis & 50 & 33 \\
TYPE III & Significant skin loss. Unable to suture without tension. High risk of secondary necrosis. & 5 & 3 \\
\hline
\end{tabular}

Table 2. Statistical analysis (ANOVA 1) of factors associated with arrival to debridement time (ADT), with injury to debridement time (IDT) and with bone fixation time (BFT).

\begin{tabular}{|c|c|c|c|}
\hline \multirow{2}{*}{ Factors } & \multicolumn{3}{|c|}{$p$ values } \\
\hline & ADT & IDT & BFT \\
\hline Material use & 0.695 & 0.000230 & 0.097 \\
\hline Cutaneous opening type & $<0.001$ & $<0.001$ & 0.876 \\
\hline Lack of financial & 0.545 & 0.289 & 0.730 \\
\hline Unavailability of care givers & 0.387 & 0.03 & 0.101 \\
\hline Radiographic down & 0.368 & 0.615 & 0.546 \\
\hline Strike of medical staff & 0.596 & 0.892 & 0.095 \\
\hline Repeat radiographic & 0.750 & 0.180 & 0.975 \\
\hline Change of team care & 0.683 & 0.496 & 0.494 \\
\hline Break fasting (ramadan period) & 0.378 & 0.945 & 0.739 \\
\hline Lower-leg local cutaneous conditions & 0.665 & 0.739 & 0.479 \\
\hline Absence of accompanying & 0.115 & 0.885 & 0.566 \\
\hline Patients flow & 0.387 & 0.03 & 0.101 \\
\hline
\end{tabular}

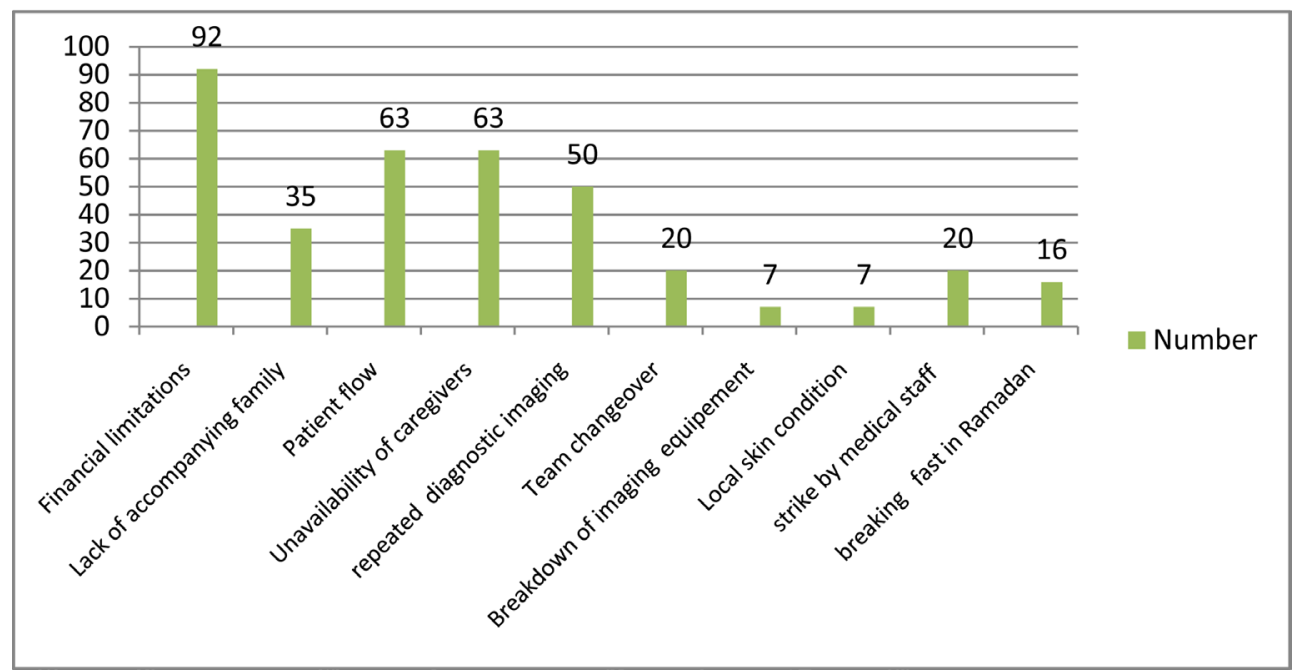

Figure 1. Causes of delay in care.

However, the association of a greater than 6 hour delay from injury to debridement with infection was not statistically significant $(p=0.403)$. 
Table 3. Infection in relation to injury to debridement time (IDT).

\begin{tabular}{rcc}
\hline & Number of patient & Percentage (\%) \\
\hline Time from injury to debridement $<6 \mathrm{~h}$ & 2 & 13.3 \\
Time from injury to debridement $>6 \mathrm{~h}$ & 13 & 86.7 \\
\hline
\end{tabular}

\section{Discussion}

\subsection{Epidemiology}

In a study from CUH Brazzaville [2] that included 122 open lower-limb fractures, more than half involved the lower-leg. Court-Brown [3] studied 2386 open fractures between 1995 and 2007, and found 267 open lower-leg fractures $(11.2 \%)$. Open lower-leg fractures are frequent injuries.

The median age of our patients and the age distribution were consistent with other studies [3] [5] [6]. Open fracture of the lower-leg particularly involves young people. Males are by far the most affected [3] [5] [7].

The most common etiology is public road accidents. Zryouil [4], 26 years earlier in the same department, also found public road accidents were the majority etiology with a rate of $71 \%$. Similarly, Moyikoua [2] found that public road accidents were the main cause $(56 \%)$, followed by assault $(23 \%)$ and falls $(6 \%)$ and other causes $(15 \%)$. Be et al. [8] published rates for public road accidents (83\%), sports injuries (7\%), assault (7\%) and falls $(3 \%)$.

\subsection{Type of Skin Incision}

In our series the most common type of open fracture were Duparc and Cauchoix type I followed by type II and type III. Zryouil [4] found $18.5 \%$ type I, 37.1\% type II and type III $44.2 \%$.On the other hand, Moyikoua [2] found that type II were the majority (46 cases), followed by type I (21 cases) and type III (11 cases); Be [8] reported only Type II (42 patients).CM Leong [9] found similar numbers of type 1 and 2 (32 and 31 cases respectively) followed by type III (17 cases).

\subsection{Collection and Admission}

Non-paramedic ambulance was the most common mean of transportation (90\%). By contrast, in a study conducted at the University Hospital of Brazzaville [2], most patients arrived at hospital by car, taxi, or motorcycle.

In France, it is usual practice for their pre-hospital service (SAMU, Service d'Aide Médicale Urgente) to stabilize patients at the accident site before transport to a health facility. SAMU mobilises units (SMUR, Service Mobile d'Urgence et Reanimation) to the scene of an accident. SMUR mobile units can be quick light vehicles, ambulances and helicopters [10].

In the United States, the priority is to evacuate the victim as early as possible to a hospital, using ambulances without a doctor, but with trained paramedics [10].

\subsection{Time and Method of Admission}

These parameters are linked to the mode of collection and admission [10]; they changed depending on the series. In Souna's series [11], $40 \%$ of patients arrived less than 6 hours post-injury. Namdari found that $58 \%$ of patients arrived less than 6 hours post-injury [12]. Kamat et al. [13] noted a median intake of 3.25 hours (62 cases). At the main hospital in Dakar [14], the median time for direct admission is 3.30 hours, with $70 \%$ arriving less than 4 hours after the accident.

\subsection{Time Taken to Request Radiography}

Hanhart [15] at the medical and surgical emergencies center in Neuchâtel, Switzerland found that median time to order an $\mathrm{x}$-ray was 1 hour, this figure is less than that found in our study.

\subsection{Time Taken to Completion of Radiographs}

Likewise these parameters vary depending on the series. Time elapsed between request and completion of diag- 
nostic imaging was 60 minutes at the Kremlin Bicêtre hospital [16]. In a study from CHU Farhat Hached in Tunisia [17], this period was 99 minutes.

\subsection{Debridement}

Debridement influences the final outcome [18]-[21]. Debridement converts a dirty wound into a clean wound, removing devitalized tissue and possible foreign elements.

The median time from injury to debridement (IDT) is variable depending on the series and is linked with the mode of transportation and admission.

So in the series of Namdari [12], Bednar [22], Beltsios [6], Hohmann [5], Kamat [13], it was $4.9 \mathrm{~h}$ for 699 patients, $8.8 \mathrm{~h}$ for 82 patients, $10 \mathrm{~h}$ for 212 patients, $5.4 \mathrm{~h}$ for 46 patients and $4 \mathrm{~h}$ for 62 patients , respectively.

\subsection{Bone Fixation}

In our study, we observed that there was time associated with prescribing the material, fixing the bone, and buying the required material after hospitalization. This was caused by the unavailability of the material used for bone fixation in our study, which consequently directly affected the time of fixation. Elsewhere in the literature, the price of bone fixation material, time of prescription, and time of purchase are not discussed. If necessary materials are immediately available in other hospital the problems we encounter will not be an issue.

Therefore the time median to bone fixation in the series of Be [8], Namdari [12], Hohmann [5], Beltsios [6] and Kamat [13] was $18 \mathrm{~h} ; 4.9 \mathrm{~h} ; 5.4 \mathrm{~h} ; 10 \mathrm{~h}$ and $4 \mathrm{~h}$ respectively.

In comparison with other series, our time is the longest. However, this has improved slightly in 26 years since1987 [4].

Many authors prefer nailing over external fixation for tibia fractures [23] [24]. However, there are still some absolute indications for external fixation [25] [26]: type III open fractures, those complicated by vascular damage, and those where treatment is delayed [27] [28]. In the series of Tripuraneni [29], he used external fixation in $78 \%$ of cases. This is comparable to our series.

\subsection{Related Injury}

In Namdari's series [12] the most common associated lesions were closed head injury, thoracic injury and abdominal injury; these lesions are also found in our series.

\subsection{Causes of Delay in Case Management}

Lack of financial resources was identified as the main cause of delay. This result is comparable to that observed in Libreville hospital center [30] where most patients were poor. Subsequent delay in purchasing equipment delays bone fixation for most poor patients. Najeb et al. [31] found similar results in their series. Be et al. [8] reported that the surgical management of trauma patients in hospitals is becoming more difficult due to the low socio-economic status of these patients and their growing numbers.

However the relationship between lack of financial resources and time to debridement or bone fixation did not reach significance $(p>0.05)$. This was true too for staff unavailability, requests for repeated radiological assessment or referral for other specialist opinions.

Sima Zue [30] reported that the shortage and unavailability of staff (porters, nurses, and technicians) were frequent causes of delay. Jarrar et al. [17] in Tunisia showed that a large influx of patients was also a cause of delayed treatment; these two factors were also found in our series and had a statistically significant association with time to debridement and bone fixation $(p<0.05)$.

Charalambous et al. [32] studied 383 cases with open lower-leg fractures presenting in seven hospitals in the north-west of England and found that delayed treatment of some fractures was due to the non-availability of an operating room or presentation of patients outside normal working hours when conditions may not be optimal. Namdari in the United States [12] found that the causes of delay are related either to patients (elderly patients, patients with head injury or severe chest trauma) or to the system of care (management protocol, availability of the surgeon, staff and operating room) and showed a statistically significant association between these factors and the time to debridement $(p<0.001)$. 


\subsection{Infection Rates}

The infection rate in our series was not significantly related to a delay to debridement of greater than six hours. $(p=0.403)$. The six-hour rule for debridement (debridement should be done within six hours of injury to avoid infection) has long been considered crucial to prevent infection [1]-[3], However it has been questioned by several authors [7] [13] [22] [33]. Twenty-one studies were reviewed by Yannascoli et al. [34]; three studies were found to support early debridement within 5 - 6 hours of injury, and the remaining eighteen studies found no correlation between time to debridement and rates of infection. Those series that found no association between early debridement and rates of infection suggest that lack of early administration of systemic antibiotics was the critical factor that may have impacted the need for urgent debridement within six hours.

We can then note in the series of Namdari [12], Bednar [22], Beltsios [6] and Hohmann [5] that the percentage of infection is $0 \%$ for a median time from injury to debridement [IDT] of $4.9 \mathrm{~h} ; 14.6 \%$ for an IDT of $8.8 \mathrm{~h}$; $17 \%$ for an IDT of $10 \mathrm{~h}$ and $4 \%$ for an IDT of $5.4 \mathrm{~h}$, respectively.

\subsection{Proposed Solutions}

Infection is the main complication of lower-leg fracture. The frequency of infection is estimated between $3 \%$ and $40 \%$ [9], and depends on several factors [35]-[37]. These factors include emergency management (antibiotic administration), the grade of open fracture, and the quality of debridement. In our study, we have identified several causes of delay. In view of these results we propose the following solutions: provide universal healthcare coverage; ensure the availability of emergency fixation equipment; increase staff numbers in the trauma centre; reserve blocks of operating theatre time exclusively for trauma management; raise public traffic awareness; better organization of mobile units for emergency rapid delivery of patients.

\section{Conclusions}

This study shows that delayed treatment of open lower-leg fractures at CUH is common, affecting a predominantly young and active population. Quicker intervention should be a priority. The Medical assistance scheme (RAMED), based on the principles of social assistance would be very helpful to the poor population and would participate in reducing our time delays. We need to repeat this study following implementation of these proposed solutions.

\section{References}

[1] Pollak, A.N. (2006) Timing of Debridement of Open Fractures. Journal of the American Academy of Orthopaedic Surgeons, 14, S48-S51.

[2] Moyikoua, A., Oko, N., Buang, B. and Mondzoto, J. (1992) Résultats du traitement initial des fractures ouvertes récentes des membres. Médecine d'Afrique Noire, 39, 755-761.

[3] Court-brown, C.M., Bugler, K.E., Clement, N.D., Duckworth, A.D. and McQueen, M.M. (2012) The Epidemiology of Open Fractures in Adults. A 15-Year Review. Injury, 43, 891-897. http://dx.doi.org/10.1016/j.injury.2011.12.007

[4] Zryouil, B., Dkhissi, M., Ouarab, M. and Trafeh, M. (1990) La fixation externe dans les fractures ouvertes de jambe. Rev. Maroc. Chir. Orthop. Traumato, 1, 74-79.

[5] Hohmann, E., Tetsworth, K. and Radziejowski, M.J. (2007) Comparison of Delayed and Primary Wound Closure in the Treatment of Open Tibial Fractures. Archives of Orthopaedic and Trauma Surgery, 127, 131-136. http://dx.doi.org/10.1007/s00402-006-0222-6

[6] Beltsios, M., Savvidou, O. and Kovanis, J. (2009) External Fixation as a Primary and Definitive Treatment for Tibial Diaphyseal Fractures. Strategies in Trauma and Limb Reconstruction, 4, 81-87. http://dx.doi.org/10.1007/s11751-009-0062-3

[7] Ashford, R.U., Mehta, M. and Cripps, R. (2004) Delayed Presentation Is No Barrier to Satisfactory Outcome in the Management of Open Tibial Fractures. Injury, 35, 411-416. http://dx.doi.org/10.1016/S0020-1383(03)00236-5

[8] Be, J., Agoh, S., Goulibaly, A., Kone, S. and Bana, A. (2001) L'enclouage centromédullaire des fractures ouvertes de jambe stade II, au delà de la $6^{\text {ème }}$ heure. Rev.Maroc.Chir.Orthop.Traumato., 11, 33-37.

[9] Leong, C.M., Leong, A.P.K. and Low, B.Y. (1988) Management of Open Tibia Fractures. Singapore Medical Journal, 29, 42-44. 
[10] Janniere, D. and Carli, P. (1995) Organisation des SAMU et SMUR, et la Réanimation pré hospitalière. In: Samii k-Anesthésie réanimation chirurgicale, 2th Edition, Flammarion Médecine et science, Paris, 1607-1700.

[11] Souna, B.S., Ganda, S., Amadou, S. and Abdoulaye, A. (2008) Le fixateur externe de Hoffmann dans la prise en charge des fractures ouvertes de jambe à Niamey. Mali Medical, 23, 11-15.

[12] Namdari, S., Baldwin, K.D. and Matuszewski, P. (2011) Delay in Surgical Debridement of Open Tibia Fractures: An Analysis of National Practice Trends. Journal of Orthopaedic Trauma, 25, 140-144.

[13] Kamat, A.S. (2011) Infection Rates in Open Fractures of the Tibia: Is the 6-Hour Rule Factor Fiction? Advances in Orthopaedics, 2011, Article ID: 943495.

[14] Potier, L. (2011) Couverture et reconstruction des segments osseux du membre inférieur à l'hôpital principal de Dakar. Maîtrise orthopédique.

[15] Hanhart, W.A., Malinverni, R. and Kehtari, R. (2006) Enquête sur les délais d'attente au Centre médico-chirurgical d'urgences, Hôpital des Cadolles, Neuchâtel. Revue Médicale Suisse, 10, 2429-2433.

[16] Muhr, G. (1991) Therapeutic Strategies in Fractures with Soft Tissue Damage. Chirurg, 62, 361-366.

[17] Jarrar, M., Khlifi, S., Amor, W.B., El Afrit, S. and Ghannouchi, S. (2005) L'accueil et la durée de la prise en charge des patients au service des urgences du CHU Farhat Hached. Journal Maghrébin D'anesthésie-Réanimation et de Médecine D'urgence, 15, 251-257.

[18] Buteera, A. and Byimana, J. (2009) Principles of Management of Open Fractures. East and Central African Journal of Surgery, 14, 2-8.

[19] Lenen, D. (2011) Fractures ouvertes de jambe: Vingt ans d'expérience d'ostéosynthèse et de chirurgie des lambeaux. E-Mémoires de L'Académie Nationale de Chirurgie, 10, 25-32

[20] Okike, K. and Bhattacharyya, T. (2006) Trends in the Management of Open Fractures. Journal of Bone and Joint Surgery, 88, 2739-2748. http://dx.doi.org/10.2106/JBJS.F.00146

[21] Zalavras, C.G. and Patzakis, M.J. (2003) Open Fractures: Evaluation and Management. Journal of the American Academy of Orthopaedic Surgeons, 11, 212-219.

[22] Bednar, D.A. and Parikh, J. (1993) Effect of Time Delay from Injury to Primary Management on the Incidence of Deep Infection after Open Fractures of the Lower Extremities Caused by Blunt Trauma in Adults. Journal of Orthopaedic Trauma, 7, 532-535. http://dx.doi.org/10.1097/00005131-199312000-00008

[23] Chapman, M.W. (1986) Therole of Intra Medullary Fixation in Open Fractures. Clinical Orthopaedics \& Related Research, 212, 26-34.

[24] Dubrana, F., Genestet, M. and Moineau, G. (2007) Fractures ouvertes de jambe. Injury, 38, 14-86.

[25] Velazco, A., Whitessides, T.E. and Fleming, L.L. (1983) Open Fractures of the Tibia Treated with the Lottesnail. Journal of Bone and Joint Surgery, 65, 879-885.

[26] Vidal, J., Buscayert, C., Connes, H., Melka, J. and Orst, G. (1983) Guidelines for Treatment of Open Fractures and Infected Pseudarthroses by External Fixation. Clinical Orthopaedics \& Related Research, 180, 83-95.

[27] Brumback, R.J., Ellison, P.S. and Poka, A. (1989) Intramedullary Nailing of Open Fractures of the Femoralsha. Journal of Bone and Joint Surgery, 71, 1324-1331.

[28] Ribault, L., Faye, M., Latouche, J.C. and Badiane, A. (1991) Bilan de 5années d'utilisation du FESSA à l'hôpital principal de Dakar. Médecine d'Afrique noire, 38, 433-441.

[29] Tripuraneni, B., Ganga, S., Quinn, R. and Gehlert, R. (2008) The Effect of Time Delay to Surgical Debridement of Open Tibia Shaft Fractures on Infection Rate. Orthopedics, 31, 1195.

[30] Zué, A.S., Josseaume, A., Nsafu, D.N, Galoisy-Guibal, L. and Carpentier, J.P. (2003) Les urgences chirurgicales au Centre Hospitalier de Libreville. Annales Françaises d'Anesthésie et de Réanimation, 22, 189-195. http://dx.doi.org/10.1016/S0750-7658(03)00008-X

[31] Najeb, Y., Abkari, I., Massous, A. and Kechkar, T. (2008) Résultats du traitement des fractures de jambe par un fixateur externe low cost d'adaptation locale. Rev.Maroc.Chi.Orthop.Traumato, 36, 14-17.

[32] Charalambous, C.P., Siddique, I., Zenios, M., Roberts, S., Samarji, R., Paul, A. and Hirst, P. (2005) Early versus Delayed Surgical Treatment of Open Tibial Fractures: Effect on the Rates of Infection and Need of Secondary Surgical Procedures to Promote Bone Union. Injury, 36, 656-661. http://dx.doi.org/10.1016/j.injury.2004.10.007

[33] Owens, B.D. and Wenke, J.C. (2007) Early Wound Irrigation Improves the Ability to Remove Bacteria. Journal of Bone and Joint Surgery, 89, 1723-1726. http://dx.doi.org/10.2106/JBJS.F.01210

[34] Yannascoli, S., Schenker, L., Ahn, J. and Mehta, S. (2011) The Urgency of Surgical Debridement and Irrigation in Open Fractures: A Systematic Review of the 6-Hour Rule. University of Pennsylvania Orthopaedic Journal, 21, 7-11. 
[35] Lima, A., Zumiotti, A., Uip, D. and Silva, J. (2004) Predictable Factors of Infection in Patients with Open Fractures in Lower Limbs. Acta Ortopédica Brasileira, 12, 32-39.

[36] Spencer, J., Smith, A. and Woods, D. (2004) The Effect of Time Delay on Infection in Open Long-Bone Fractures. Annals of the Royal College of Surgeons of England, 86, 108-112. http://dx.doi.org/10.1308/003588404322827491

[37] Kohlprath, R., Assal, M. and Uçkay, I. (2011) Fractures ouvertes de la diaphyse tibiale chez l'adulte: Prise en charge chirurgicale et complications. Revue Médicale Suisse, 7, 2482-2488. 
Scientific Research Publishing (SCIRP) is one of the largest Open Access journal publishers. It is currently publishing more than 200 open access, online, peer-reviewed journals covering a wide range of academic disciplines. SCIRP serves the worldwide academic communities and contributes to the progress and application of science with its publication.

Other selected journals from SCIRP are listed as below. Submit your manuscript to us via either submit@scirp.org or Online Submission Portal.
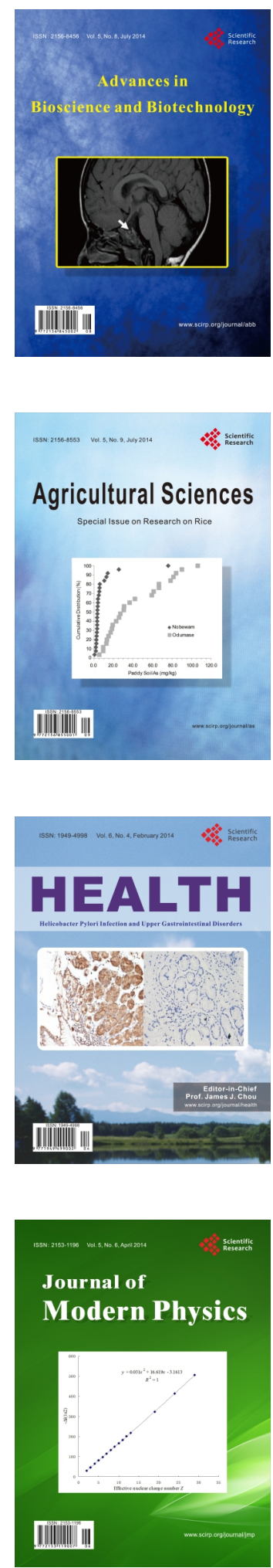
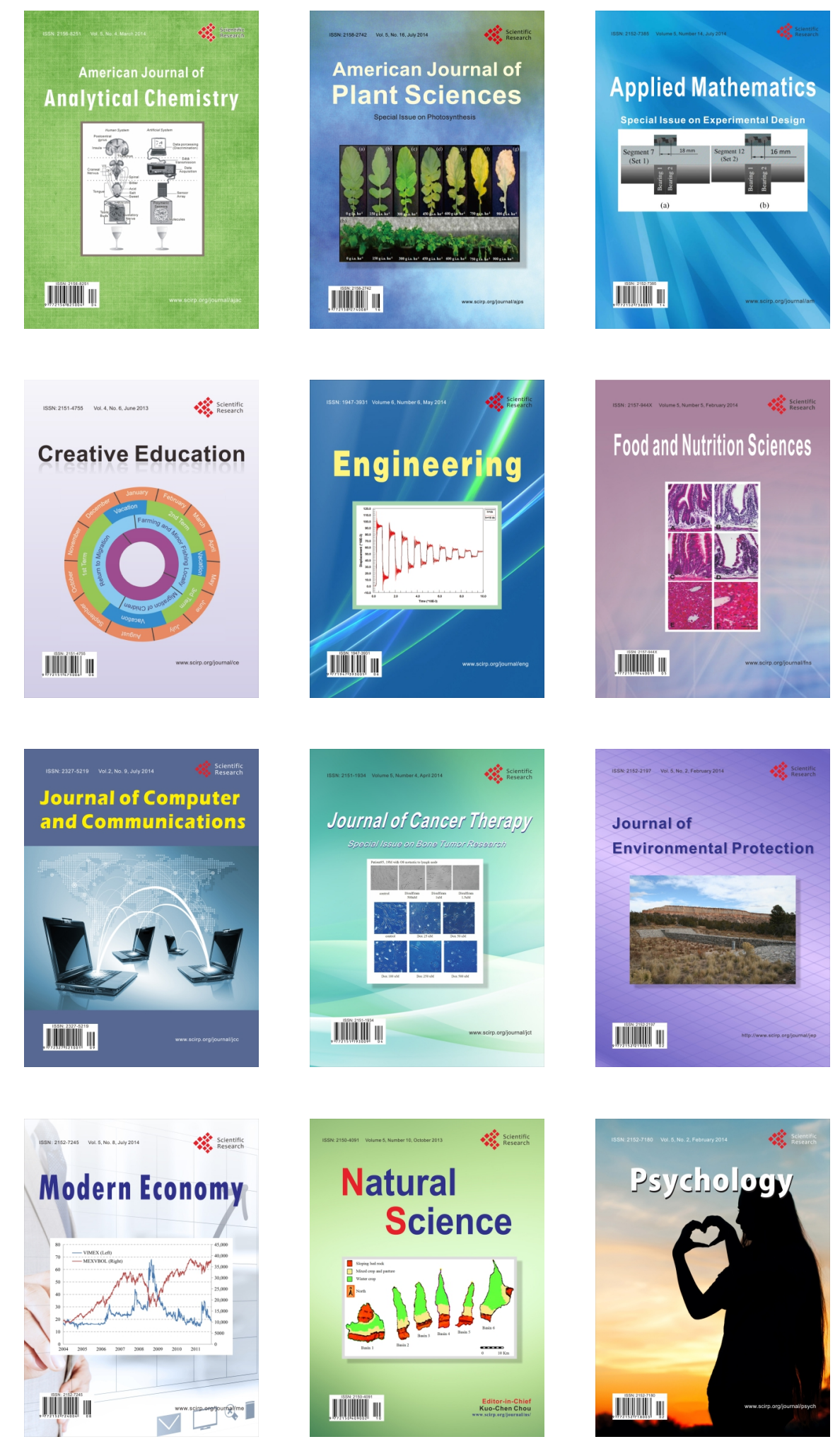